\title{
17 Life under Conditions of Ionizing Radiation
}

Christa Baumstark-Khan and Rainer Facius

Life on Earth, throughout its almost 4 billion years history, has been shaped by interactions of the organisms with their environment. It has developed with an ever present radiation background. As a powerful mutagen it has contributed to biological evolution, however, it is potentially destructive for individual cells and organisms [1]. Radiation response differs extremely for different organisms and there is not necessarily a correlation between species radiation resistance and levels of exposure in the natural environment [2].

In our solar system Earth is not the only planet, which had the capacity to provide the prerequisites for sustaining life. Mars and the Jupiter moon Europa are suggested to have had the capacity to support life, at least for a certain era. The detection of meteorites on Earth that originate from Mars supports the theory of interplanetary transfer of life (see Chapter 4, Horneck et al.). Life on other planets or while it is transported through space environment encounters radiation conditions different from those on Earth.

In order to understand the likelihood of the development and the chance of persistence of life on Earth or other planets, following questions have to be asked:

1. What is the "normal" radiation environment under which life flourishes on Earth?

2. What is the "worst case" radiation environment that life will encounter in space?

3. How does radiation interact with living matter and how does life actively modulate radiation effects?

\subsection{Space Radiation Environments}

From outer space regions, which are characterized by extreme conditions involving nuclear and atomic reactions (very high temperatures, low density and high-speed subatomic particles) electromagnetic radiation (X-rays and $\gamma$-rays) is emitted which consist of soft X-rays, from about 1 to $10 \mathrm{~nm}$ of wavelength and of the more penetrating hard X-rays from approximately 0.01 to $1 \mathrm{~nm}$. The space ionizing radiation environment of our galaxy [3-9] is dominated by energetic, highly penetrating ions and nuclei. These particles constitute the primary radiation hazard for life in space. In the interplanetary space the primary components of the radiation field (Figure 17.1, Table

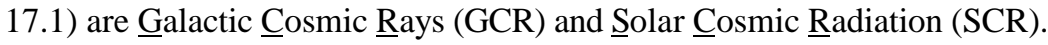




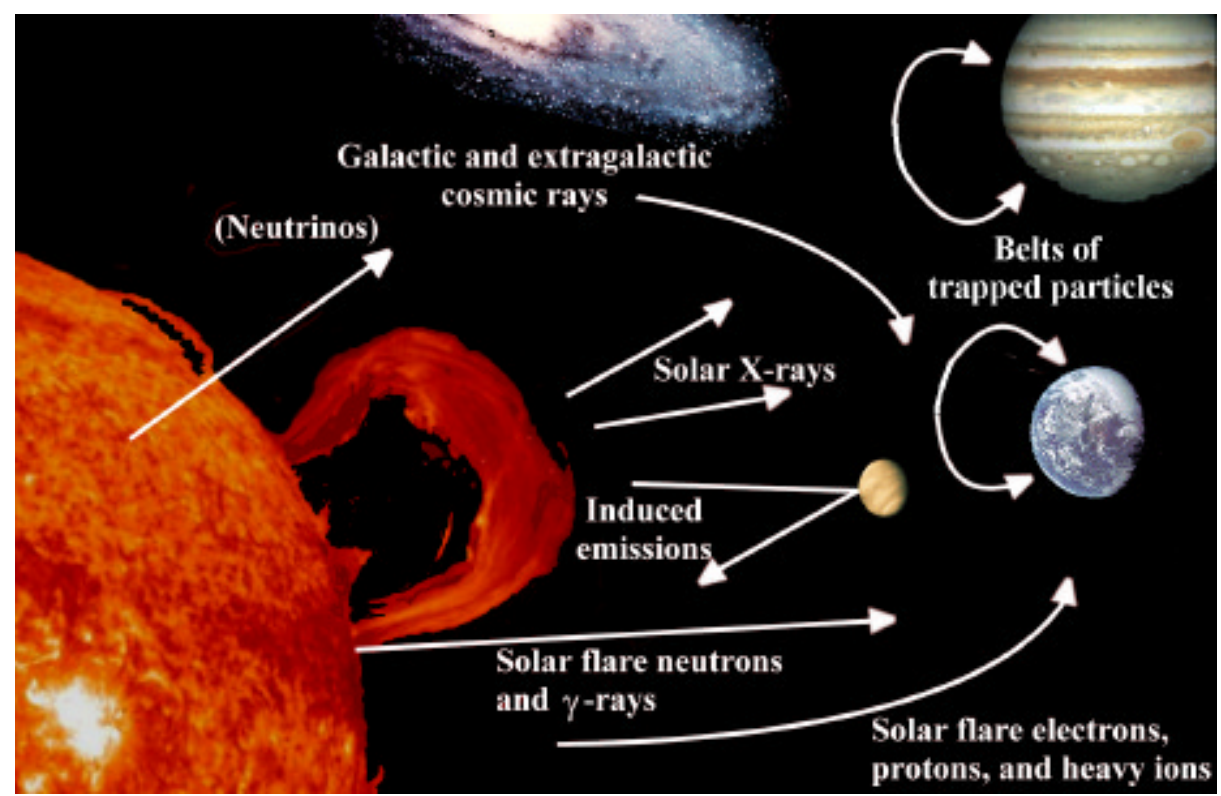

Fig. 17.1 Space radiation sources of our solar system

Table 17.1 Summary of High Energy Space Radiation Sources

\begin{tabular}{llll}
\hline Radiation Source & $\begin{array}{l}\text { Influence of } \\
\text { solar cycle }\end{array}$ & Additional modifiers & $\begin{array}{l}\text { Types of orbits } \\
\text { affected }\end{array}$ \\
\hline $\begin{array}{l}\text { galactic cosmic ray } \\
\text { ions }\end{array}$ & $\begin{array}{l}\text { solar min: higher flux; } \\
\text { solar max: lower flux }\end{array}$ & distance from the sun & $\begin{array}{l}\text { LEO; GEO; HEO; } \\
\text { interplanetary trajecto- } \\
\text { ry }\end{array}$ \\
\hline $\begin{array}{l}\text { solar particle events } \\
\text { (protons, heavy ions) }\end{array}$ & $\begin{array}{l}\text { large Numbers during } \\
\text { solar max; few during } \\
\text { solar min }\end{array}$ & $\begin{array}{l}\text { distance from the sun; } \\
\text { location of flare on } \\
\text { sun }\end{array}$ & $\begin{array}{l}\text { LEO }\left(\mathrm{I}>45^{\circ} \text { ); GEO; }\right. \\
\text { HEO interplanetary }\end{array}$ \\
\hline trapped protons & $\begin{array}{l}\text { solar min: higher flux; } \\
\text { solar max: lower flux }\end{array}$ & $\begin{array}{l}\text { geomagnetic field; } \\
\text { solar flares; geo- } \\
\text { magnetic storms }\end{array}$ & $\begin{array}{l}\text { LEO; HEO; } \\
\text { transfer orbits }\end{array}$ \\
\hline * low earth orbit (LEO); geostationary orbit (GEO); highly elliptical orbits (HEO); inclination (I); \\
\hline
\end{tabular}

\subsubsection{Galactic Cosmic Radiation (GCR)}

The spectrum of GCR is fairly well known. GCR originates from outside our solar system and consist of $98 \%$ baryons and $2 \%$ electrons [3]. The baryonic component is composed of $87 \%$ protons (hydrogen nuclei), $12 \%$ alpha particles (helium nuclei), and about $1 \%$ of heavier nuclei. (The latter are fully ionized ions of all elements from protons (atomic number $\mathrm{Z}=1$ ) to uranium $(\mathrm{Z}=92)$. These particles are predominantly 
accelerated in the Milky Way. At the very highest energies, the particles are actually assumed to be extra-galactic; that is, originating from powerful astrophysical accelerators, such as supernova explosions, or quasars, located outside of the Milky Way.

The composition and energy spectra of GCRs change during their passage through the Galaxy, due to collisions between the GCRs and interstellar gas. The intensities and energy spectra also depend upon location in space. When GCRs enter our Solar System, they must overcome the outward-flowing solar wind. The magnetic field transported with the solar wind deflects and thereby attenuates the particle fluxes at lower energies as they penetrate into the heliospere [4]. The intensity of the solar wind varies according to the about 11-year cycle of solar activity and hence the GCR fluxes also vary with the solar cycle, an effect known as solar modulation. GCR flux is at its peak level during minimum solar activity and at its lowest level during maximal solar activity [5]. Differences between solar minimum and solar maximum are a factor of approximately five.

The energy range of GCRs extends over more than fifteen orders of magnitude, from less than $1 \mathrm{MeV}\left(=10^{6} \mathrm{eV}\right)$ to more than $10^{21} \mathrm{eV}$ [3]. At peak energies of about $200-700 \mathrm{MeV} / \mathrm{u}$, particle fluxes (flow rates) during solar minimum reach $2 \times 10^{3}$ protons per year per $\mu \mathrm{m}^{2}$ and $0.6 \mathrm{Fe}$-ions per year per $\mu \mathrm{m}^{2}$. Since dose is proportional to the square of the particle's charge the iron ions contribute nevertheless a significant part to the total radiation dose. Above about $1 \mathrm{GeV} / \mathrm{u}$ particle fluxes decrease according to a power law with an exponent of approximately 2.5 .

\subsubsection{Solar Particle Radiation (SPR)}

SPR consists of the low energy solar wind particles that flow constantly from the sun and the so-called highly energetic solar particles events (SPEs) that originate from magnetically disturbed regions of the sun which sporadically emit bursts of energetic charged particles [6]. They are composed predominantly of protons with a minor contribution from helium ions ( $10 \%)$ and an even smaller part (1\%) heavy ions and electrons [7]. SPEs develop rapidly and generally last for no more than some hours, however some proton events may continue over several days. In a worst case scenario the emitted particles can reach energies up to several $\mathrm{GeV}$, resulting in physically absorbed doses as high as $10 \mathrm{~Gy}$ to be received within a short time. The average eleven year cycle of solar activity can be divided into four inactive years with a small number of SPEs around solar minimum and seven active years with higher numbers of SPEs around solar maximum [8]. During the solar minimum phase, few significant SPE occur while during each solar maximum phase large events may occur even several times. For example, in cycle 22 (1986-1996) there were at least eight events for proton energies greater than $30 \mathrm{MeV}[9]$.

\subsubsection{Radiation Belts in Planetary Magnetic Fields}

In the vicinity of the planets with magnetic fields, a third radiation component is present: energetic charged particles trapped by planetary magnetic fields in the so-called radiation or Van Allen belts [10]. The belts are toroidal regions of trapped protons and 
both inner and outer electron belts. These toroidal regions in the equatorial plane of the planetary magnetic dipole contain large fluxes of high-energy, ionized particles including electrons, protons, and some heavier ions. In each zone, the charged particles spiral around the magnetic field lines and are reflected back between the magnetic poles, acting as mirrors. Electrons in the Earth's Van Allen belts reach energies of up to $7 \mathrm{MeV}$ and protons up to $600 \mathrm{MeV}$. The energy of trapped heavy ions is less than 50 $\mathrm{MeV} / \mathrm{u}[11]$.

\subsubsection{Modulation by Planetary Magnetic Fields, Atmospheres and Surfaces}

Planetary magnetic fields, which on the one hand give rise to sources in trapped radiation belts, provide on the other hand efficient shielding against solar and cosmic particles. Incoming GCR and SPR particles are deflected by the magnetic fields, so that only regions around the magnetic poles are fully accessible to external charged particle radiation, whereas regions around the magnetic equators can only be reached by the most energetic particles [4, 12].

In contrast to shielding by magnetic fields, planetary atmospheres give rise to an initial build-up of radiation levels. This build-up is created by numerous secondary reaction products, which are generated in spallation and fragmentation reactions between the incoming primary particles and the nuclei of atmospheric constituents [13]. Only after significant amounts of matter (approx. $50 \mathrm{~g} / \mathrm{cm}^{2}$ ), total radiation levels start to decrease, so that after $1000 \mathrm{~g} / \mathrm{cm}^{2}$ the radiation intensity has been reduced to less than about 0.3-1 mGy/year which we normally observe at sea level on Earth.

On celestial bodies without atmospheres, the same mechanisms (spallation and fragmentation) generate significant fluxes of energetic "albedo" neutrons, which are reflected from the irradiated surface and ground [14] and thereby add to the radiation exposure from primary radiation (SCR and GCR).

\subsection{Radiation Environments on Planets and Other Celestial Bodies}

Natural ionizing radiation on the surface of planets arises from two sources: extraterrestrial (primary cosmic rays and secondary radiation) and terrestrial. Terrestrial radiation [15] is emitted by radioactive nuclides in rocks, soil and the hydrosphere of the planets' crusts which were formed at the birth of the planet and which persist due to their long half-lives plus the emergence of decay products (primordial radionuclides). In the atmosphere most of the radionuclides are secondary products induced by the GCRs (cosmogenic radionuclides). Some of these radionuclides can be transferred to cells and organisms and for this reason exposures may be of internal as well as of external origin. 


\subsubsection{Earth}

On Earth, the primordial radionuclides consist mainly of the natural decay series (Table 17.2) with the exception of the already extinct neptunium series. Other examples of socalled radio-fossils are ${ }^{40} \mathrm{~K}$ and ${ }^{87} \mathrm{Rb}$. Essentially, exposure from external irradiation comes from ${ }^{40} \mathrm{~K}$ and the $\gamma$-emitting intermediate products of the persisting decay series. There are considerable geographic variations of the natural radiation due to varying concentrations of radionuclides in soil and minerals. For so-called normal areas, background radiation from radionuclides lies in the range of $1 \mathrm{mGy}$ per year [16]. However, there are certain areas with higher background radiation levels around the world. For an area in China dose rates of about 3-4 mGy/year have been reported [17] and on the Southwest coast of India the doses from external radiation by monazite deposits is 5-6 mGy/year with maximal doses up to $32.6 \mathrm{mGy} / y e a r$ [18]. Along certain beaches in Brazil where monazite sand deposits are found external radiation levels range up to $400 \mathrm{mGy} /$ year [19].

Earth is largely protected from the cosmic radiation by the deflecting effect of the geomagnetic field and the huge shield of $1000 \mathrm{~g} / \mathrm{m}^{2}$ provided by the atmosphere. The annual dose from cosmic radiation varies somewhat with latitude and considerably with altitude, approximately doubling every $1500 \mathrm{~m}$ up to a few $\mathrm{km}$ above sea level. Typical cosmic radiation doses for Germany [20] are $0.3 \mathrm{mGy} / \mathrm{year}$ at sea level (Hamburg), $0.5 \mathrm{mGy} /$ year at $1000 \mathrm{~m}$ (Garmisch-Partenkirchen), $1.2 \mathrm{mGy} / \mathrm{year}$ at $3000 \mathrm{~m}$ (Zugspitze) and up to $25 \mathrm{mGy} / \mathrm{year}$ at $15 \mathrm{~km}$ altitude.

\subsubsection{Mars}

Unlike Earth, Mars is devoid of an intrinsic magnetic field (see Chap. 13, Lammer et al.) allowing many of the free-space high-energy charged particles to reach the outer atmosphere. However, the carbon dioxide atmosphere of Mars significantly attenuates the charged particle fluxes and provides a significant amount of protection. The Mars surface environment is exposed to GCR, particles from SPEs and secondary products generated by these particles within the Martian atmosphereand surface materials [21-

Table 17.2 Natural decay series of the Earth crust

\begin{tabular}{|c|c|c|c|}
\hline Name & Start nucleus & Final nucleus & $\begin{array}{c}\text { Half-live } \tau \text { of the } \\
\text { start nucleus }\end{array}$ \\
\hline Thorium series & ${ }_{90}^{232} \mathrm{Th}$ & ${ }_{82}^{208} \mathrm{~Pb}$ & $1.4 \times 10^{10}$ years \\
\hline Neptunium series & ${ }_{93}^{237} \mathrm{~Np}$ & ${ }_{83}^{209} \mathrm{Bi}$ & $2.2 \times 10^{6}$ years \\
\hline Uranium-radium series & ${ }_{92}^{238} \mathrm{U}$ & ${ }_{82}^{206} \mathrm{~Pb}$ & $4.5 \times 10^{9}$ years \\
\hline Uranium-actinium series & ${ }_{92}^{235} \mathrm{U}$ & ${ }_{82}^{207} \mathrm{~Pb}$ & $7.1 \times 10^{8}$ years \\
\hline
\end{tabular}


23]. A prominent feature of the surface radiation environment is the large number of neutrons produced as secondaries. For neutron energies below $20 \mathrm{MeV}$, the backward propagating neutrons from the GCR hitting the ground are predicted to dominate those produced in the atmosphere. The backward propagating neutrons from giant SPEs are believed to be nearly equal in number to those produced in the atmosphere.

The calculation of physically absorbed radiation doses on the surface of Mars depends on the assumed density profile of the Martian atmosphere and is further limited by an as yet complete description of the physical interactions of heavy charged particles with nuclei of the Martian atmosphere and Martian surface. Table 17.3 shows calculated physically absorbed dose values for GCRs and SPRs at various Martian altitudes for different atmospheric models, which were derived from measurements during the Viking 1 and Viking 2 entries [23]. From these data the COSPAR warm, high-density atmosphere model (HDM) and the COSPAR cool, low-density atmosphere model (LDM) were developed, which result in different radiation exposures. More information will soon be brought about by the Mars Odyssey Mission 2001, which launched on April 7, 2001. It will reach the red planet in October 2001 where it will study its composition, search for water and shallow buried ice, plus measure solar and cosmic radiation. It carries a spectrometer, the Mars Radiation Environment (MARIE) experiment which will measure the accumulated dose and dose rate as a function of time, determine the radiation quality factor, determine the energy deposition spectrum from $0.1 \mathrm{keV} / \mu \mathrm{m}$ to $1500 \mathrm{keV} / \mu \mathrm{m}$ and separate the contribution of protons, neutrons and HZE particles to these quantities.

Table 17.3 Mars physically absorbed surface radiation doses at different atmospheric shielding levels. Calculations are based on the atmospheric conditions described by the COSPAR LDM and the COSPAR HDM. Data are taken from [23].

\begin{tabular}{llcccc}
\hline Altitude (km) & & $\mathbf{0}$ & $\mathbf{4}$ & $\mathbf{8}$ & $\mathbf{1 2}$ \\
\hline Atmospheric density $\left(\mathrm{g} / \mathrm{cm}^{2} \mathrm{CO}_{2}\right)$ & $\mathrm{LDM}$ & 16 & 11 & 7 & 5 \\
& $\mathrm{HDM}$ & 22 & 16 & 11 & 8 \\
\hline GCRs at solar minimum (mGy/a) & LDM & 57 & 61 & 65 & 68 \\
& HDM & 53 & 57 & 61 & 64 \\
\cline { 2 - 6 } GCRs at solar maximum (mGy/a) & LDM & 27 & 27 & 28 & 28 \\
& HDM & 26 & 27 & 27 & 28 \\
\hline SPR August 1989 (mGy/event) & LDM & 3 & 9 & 26 & 68 \\
SPR October 1989 (mGy/event) & HDM & 1 & 3 & 9 & 23 \\
\cline { 2 - 6 } & LDM & 32 & 82 & 189 & 416 \\
& HDM & 12 & 33 & 79 & 171 \\
\hline
\end{tabular}




\subsubsection{Jupiter's Moon Europa}

Interest in Jupiter's moon Europa has intensified with exciting new findings in the last few years from NASA's Galileo mission. Perhaps the most exciting facet of Europa is that an ocean of liquid water may lie beneath its ice surface (see Chap. 7, Greenberg). The Committee on Planetary and Lunar Exploration (COMPLEX) considered Europa an exciting object for further study, with the potential for major new discoveries in planetary geology and geophysics, and the potential for studies of extraterrestrial life.

Jupiter is a rapidly rotating planet with a very strong prototypical rotationally driven magnetic field [24]. Data from the two Pioneer and the two Voyager spacecrafts indicated that its pea-shaped magnetosphere extends up to $3-7 \times 10^{6} \mathrm{~km}$ towards the Sun whereas its tail is stretched up to a distance of $7.5 \times 10^{8} \mathrm{~km}$ in the opposite direction. Its strong magnetic field makes Jupiter the strongest radio emitter in the Solar System after the Sun. The non-thermal radiation as a signature of Jupiter's radiation belts is a type of synchrotron radiation, and it results from high-energetic free electrons which travel nearly the speed of light in spirals shaped by the magnetic field lines.

The large Galilean satellites are embedded within Jupiter's magnetosphere and Io is known to be a source of ions and neutral particles [24]. Ions, predominantly of sulfur and oxygen, are distributed along the orbit of Io to form a large torus. Electrons and ions from Io and Jupiter's ionosphere are present throughout the Jovian magnetosphere. A substantial fraction of these particles are accelerated to extremely high energies to form intense radiation belts. The planet's inner radiation belt is analogous to Earth's Van Allen belts, but about $0.5-1 \times 10^{4}$ times more intense. The harshest radiation conditions - unmatched elsewhere in the Solar System - prevail within about $3 \times 10^{5} \mathrm{~km}$ off the giant planet.

Europa lies deep within the magnetosphere of Jupiter. It is located in the inner magnetosphere of Jupiter (at a radial distance of $\sim 9.5 R_{J} \cong 6.7 \times 10^{5} \mathrm{~km}$ ), a region populated mainly by plasma derived from the Io plasma torus [25]. The plasma there consists of protons, oxygen and sulfur ions, and their corresponding electrons. Europa is continually bombarded by magnetically trapped, ionizing radiation. This magnetospheric particle flux is the dominant component of the radiation environment at Europa. Galactic cosmic radiation and solar particle radiation cannot access Europa because of Jupiter's magnetic field except at energies exceeding $\sim 90 \mathrm{GeV}$, where fluxes are negligible.

The intensity of the radiation environment in the Jupiter system has been measured by several spacecrafts. Data on the radiation environment of Europa have been compiled from information gathered by the Pioneer 10 and 11, Voyager 1 and 2, and Galileo missions [24, 26]. Available measurements include electron intensities in the energy range $30 \mathrm{keV}$ to $>10 \mathrm{MeV}$ and ion intensities from $30 \mathrm{keV}$ to $>100 \mathrm{MeV}$. Data on ion composition - separation of protons from helium and from ions with atomic number $\mathrm{Z}>6$ - are available above about $500 \mathrm{keV} / \mathrm{u}$. These data are input to standard models for physically absorbed radiation doses that calculate the rate of energy deposition versus depth below the target surface [27]. These results are summarized in Figure 17.2, which shows the radiation dose rate deposited at various depths in the Europan ice. Contributions from Jovian electrons and electron bremsstrahlung are 


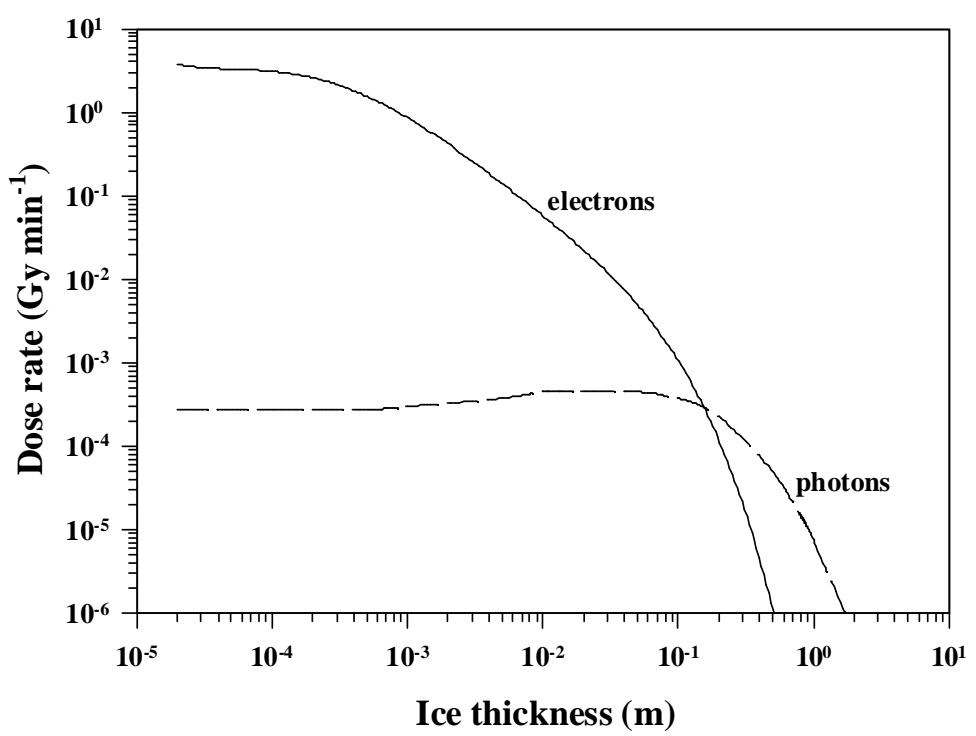

Fig. 17.2 Rates of physically absorbed radiation doses for Europa, in Gy per min of exposure below varying thicknesses of ice [modified, from 27]. The separate contributions of electrons and photons (bremsstrahlung) are shown. In addition to the theoretical uncertainties in Europa's radiation environment, natural variations of up to an order of magnitude have been observed in Jupiter's trapped-particle intensities over the 25-year span between the Pioneer and Galileo missions.

shown. The contribution from ions and electrons with energies below $30 \mathrm{keV}$ may be ignored due to their restricted penetration range $(10 \mu \mathrm{m})$.

\subsection{Measures of Ionizing Radiation}

\subsubsection{Physical Measures}

Exposure to ionizing radiation historically has been measured by use of ionizing chambers for $\mathrm{X}$ or $\gamma$-radiation. The measure of exposure has been the number of ion pairs generated in dry standard air. In the international system (SI), the corresponding unit is Coulomb per kilogram.

A more general measure of exposure to ionizing radiation is the amount of energy deposited per unit mass by ionizing radiation in matter. The corresponding SI-unit for the so-defined (physically) absorbed dose is the Gray ( $1 \mathrm{~Gy}=1$ Joule per kilogram). In radiation biology, the energy absorbed per unit mass of living tissue has to be determined. 


\subsubsection{Biologically Weighted Measures}

The physical unit Gy, however, does not determine the biological effects of the different types of radiation, such as X-rays and $\gamma$-rays, $\alpha$-particles, $\beta$-particles, neutrons and heavy ions. Instead, for a given dose in Gy, the biological effects differ with the type of radiation. A dose of energetic charged particles normally causes more damage than the same dose of energetic photons (X-rays or $\gamma$-rays). Particles with high atomic numbers and high energy (HZE particles) cause the greatest damage for a given dose.

The relative biological effectiveness (RBE) is used to express the relative amount of biological damage caused by a given dose deposited by a particular type of ionizing radiation for a specific biological endpoint. For a given test radiation, it is calculated as the dose of a reference radiation, usually X-rays, required to produce the same biological effect as with a test dose, $\mathrm{D}_{\mathrm{T}}$, of another radiation [28]. Thus, the value of the RBE provides a quantitative index of the effectiveness per unit of absorbed dose of any radiation. It can be experimentally determined for certain end-points and certain tissues or organisms. The RBE value for a given type of radiation usually is different for different biological systems (e.g. different organisms) or for different stages of the same system (e.g. stage in the growth cycle or other environmental factors, e.g. oxygen content). For higher organisms, such as mammalian cells, a lot of data exist, which describe RBE values as high as 20 .

The primary physical feature which determines the RBE of different types of ionizing radiation is the spatial density of ionizations produced per unit absorbed dose in the irradiated tissue. Figure 17.3 gives a schematic example of this concept together with the visualization of ionization densities produced by different types of radiation in nuclear emulsions. $\gamma$-irradiation produces ionizations homogeneously within a cell, whereas densely ionizing radiation tends to produce clusters of ionization (Fig. 17.3) that are believed to cause more serious damage to the cells.

As a substitute for the spatial ionization density the Linear Energy Transfer (LET) has been introduced for its quantification. This LET [28] is defined as the average amount of energy lost per unit of particle track length, and commonly is expressed in $\mathrm{keV} \mu \mathrm{m}^{-1}$.

In order to quantify the RBE of different types of ionizing radiation for purposes of human radiation protection the so-called quality or radiation-weighting factor $\mathrm{Q}$ has been defined. The product of Q with the physically absorbed dose yields the so-called "equivalent dose", the SI unit of which is the Sievert (Sv).

\subsection{Interaction of Radiation with Biological Material}

Radiation, both, of terrestrial and cosmic origin, is a persistent stress factor, life has to cope with. Radiation interacts with matter primarily by ionization and excitation of the electrons in atoms and molecules. These matter-energy-interactions have ever been present during the creation and maintenance of living systems on Earth. Exposure with ionizing radiation leads to the development of reactive species in different solvents. Water (see Chap. 5, Brack) is the main constituent of all living systems. In somatic 


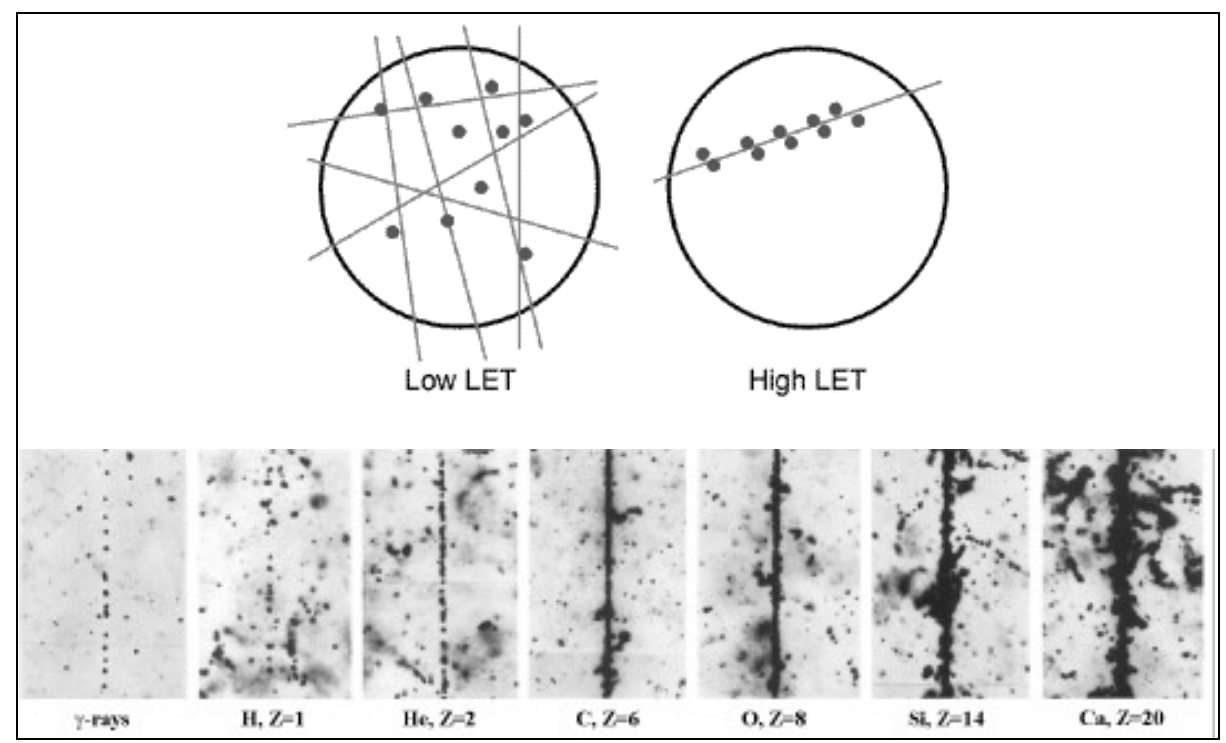

Fig. 17.3 Distribution of ionizations in equal volumes by low and high LET radiation and tracks in photo-emulsions of electrons produced by $\gamma$-rays and tracks of different nuclei of the primary cosmic radiation moving at relativistic velocities (modified from [29]). For biological radiation effects the efficiency of a radiation type increases as the ion density along the tracks increases.

and vegetative cells its fraction lies between 40 and $70 \%$, even in bacterial spores it amounts still around $20 \%$.

\subsubsection{Radiation Chemistry of Water}

Most of the energy of ionizing radiation is absorbed by water molecules [30-32], which are either excited or ionized (Eq. 17.1). Excitation of a water molecule is often followed by splitting of the molecule (Eq. 17.2).

$$
\begin{array}{ll}
\mathrm{H}_{2} \mathrm{O} \stackrel{h \cdot v}{\longrightarrow} \mathrm{H}_{2} \mathrm{O}^{+}+e_{a q}^{-} & \text {(Ionization) } \\
\mathrm{H}_{2} \mathrm{O} \stackrel{h v}{\longrightarrow} \mathrm{H}^{\bullet}+{ }^{\bullet} \mathrm{OH} & \text { (Splitting) }
\end{array}
$$

The primary products are $\mathrm{H}^{\bullet},{ }^{\bullet} \mathrm{OH}, \mathrm{H}_{2} \mathrm{O}^{+}$and electrons. All these species possess unpaired electrons, thus being highly reactive free radicals [33]. The electron is particularly reactive, it captures another water molecule thus forming a negatively charged ion (Eq. 17.3).

$$
\mathrm{H}_{2} \mathrm{O}+\mathrm{e}_{\mathrm{aq}}^{-} \longrightarrow \mathrm{H}_{2} \mathrm{O}^{-}
$$

The ions $\mathrm{H}_{2} \mathrm{O}^{+}$and $\mathrm{H}_{2} \mathrm{O}^{-}$are not stable, they do not persist in this form as they dis- 
sociate almost immediately $\left(10^{-16}\right.$ seconds) into $\mathrm{H}^{+}$ions and ${ }^{\circ} \mathrm{OH}$ radicals as well as into ${ }^{-} \mathrm{OH}$ ions and $\mathrm{H}^{\bullet}$ radicals (Eq. 17.4).

$$
\begin{aligned}
& \mathrm{H}_{2} \mathrm{O}^{+} \longrightarrow \mathrm{H}^{+}+{ }^{\bullet} \mathrm{OH} \\
& \mathrm{H}_{2} \mathrm{O}^{-} \longrightarrow \mathrm{H}^{\bullet}{ }^{-} \mathrm{OH}
\end{aligned}
$$

Commonly, there will be a number of reactions among the free radicals themselves, thereby either reconstituting water (Eq. 17.5) or forming molecular hydrogen and hydrogen peroxide (Eq. 17.6). The interactions of free radicals both among themselves and with their own reaction products is dependent primarily on how closely they have been formed. After they are formed, they must diffuse through the medium until they encounter something with which they may interact. The probability of these reactions are favored within spurs, blobs and tracks. Interactions with other solute molecules are only possible, if the primary species are able to escape these zones.

$$
\begin{aligned}
& e_{a q}^{-}+\mathrm{H}^{+} \longrightarrow \mathrm{H}_{2} \mathrm{O} \\
& \mathrm{H}^{\bullet}+{ }^{\bullet} \mathrm{OH} \longrightarrow \mathrm{H}_{2} \mathrm{O} \\
& e_{a q}^{-}+\mathrm{H}_{2} \mathrm{O}^{-} \longrightarrow \mathrm{H}_{2}+2^{-} \mathrm{OH} \\
& { }^{\bullet} \mathrm{OH}+{ }^{\bullet} \mathrm{OH} \longrightarrow \mathrm{H}_{2} \mathrm{O}_{2}
\end{aligned}
$$

(Recombination)

Densely ionizing radiations ( $\alpha$ particles, protons, electrons) produce clusters of ions that are very close together [34]. These ions may subsequently dissociate into closely associated free radicals, which do not need to diffuse far before encountering something to interact with. Consequently, there will be a high probability of interactions between free radicals and with the products of previous radical-radical interactions.

If ionizations are brought about by sparsely ionizing radiation, the clusters of ions formed are more widely separated than those produced by densely ionizing radiation. The probability of interactions between the resultant free radicals is much smaller than that following irradiation with densely ionizing particles. Energy transfer from ionizing radiation and accordingly the number of free-radical interactions increases within a given volume. As the density of ionization increases (with increasing LET), there is also an increase in the number of changed molecules and thus an increase of radiation effects in cells.

So far only reaction in the absence of oxygen have been considered. Since this molecule plays an important role in living systems its significance in radiation biology has to be elucidated. The oxygen molecule is a reaction partner for the primary radiolytic products, the electron and the hydrogen radical (Eq. 17.7). It does not react with the ${ }^{\circ} \mathrm{OH}$.

$$
\begin{aligned}
& e_{a q}^{-}+\mathrm{O}_{2} \longrightarrow \mathrm{O}_{2}^{-} \\
& \mathrm{H}^{\bullet}+\mathrm{O}_{2} \longrightarrow \mathrm{HO}_{2}^{\bullet} \longleftrightarrow \mathrm{O}_{2}^{-}+H^{+}
\end{aligned}
$$

Both, $\mathrm{HO}_{2}{ }^{-}$and $\mathrm{O}_{2}^{-}$are unstable and enter easily further reactions. In solutions containing oxygen, there is an increased formation of hydrogen peroxide while oxygen 
is partly regenerated (Eq. 17.8). There are, however, other reactions which have to be taken into account. The most important is the decomposition of hydrogen peroxide thus increasing the yield of the hydroxyl radical (Eq. 17.9).

$$
\begin{aligned}
& \mathrm{O}_{2}^{-}+\mathrm{O}_{2}^{-} \longrightarrow \mathrm{H}_{2} \mathrm{O}_{2}+\mathrm{O}_{2} \\
& \mathrm{HO}_{2}^{\bullet}+\mathrm{HO}_{2}^{\bullet} \longrightarrow \mathrm{H}_{2} \mathrm{O}_{2}+\mathrm{O}_{2} \\
& e_{a q}^{-}+\mathrm{H}_{2} \mathrm{O}_{2} \longrightarrow \stackrel{\mathrm{OH}}{\longrightarrow} \mathrm{OH}^{-}
\end{aligned}
$$

It has been shown, that highly reactive species are formed by water radiolysis. They are not only able to react with each other but also with solved molecules such as organic molecules. Thus, biological key substances such as proteins, RNA and DNA cannot only be inactivated by direct energy absorption (direct radiation effect) but also via interactions with radicals (indirect radiation effect) [35-37].

For the direct radiation effect, the mean number of inactivated molecules is directly proportional to the dose, whilst for the indirect effect the number of inactivated molecules depends on the dose and on their concentration. For more dilute solutions, there is a greater yield of damaged molecules per dose (more radicals per solute molecule) than for more concentrate solutions (less radicals per solute molecule). Only for extremely diluted solutions, this effect is reduced, due to greater diffusion distances for radicals and their higher recombination probability. The protective influence of low temperatures on biological systems (up to a factor of 100) can be attributed to reduced diffusion capabilities of radials in frozen water and thus to a perturbed reactivity with the solute molecules. As the formation of free radicals from ionized water is the major mechanism through which the indirect action of radiation proceeds, the degree of hydration of a living system is expected to influence its radiosensitivity. The greater the water content of cells is, the greater is the number of free radicals and thus the number of interactions. In dry systems, most of radiation action is thus attributable to the direct effect.

\subsubsection{DNA Damage and Cellular Repair Pathways}

The genetic material of all living organisms, both eukaryotes and prokaryotes as well as of most viruses, consists of deoxyribonucleic acid (DNA).

DNA is the most important molecule for living beings from two aspects. It contains all the information for structure and function (via the matrix function of DNA for the transcription step during protein biosynthesis) of each cell in a whole organism and it has the capacity to replicate accurately so that progeny cells have the same genetic information as the parental cell. For the continuous maintenance and circulation of life, the chemical stability of DNA is one of the prerequisites. In addition, the genetic material must be capable of variation, one of the bases for evolutionary change.

DNA consists of two associated polynucleotide strands that wind together in a helical fashion, called double helix. Each polynucleotide strand is a linear polymer in which the monomers (deoxynucleotides), are linked together by means of phosphodiester bonds. These bonds link the 3 ' carbon in the ribose of one deoxynucleotide to the 
5' carbon in the ribose of the adjacent deoxynucleotide. The four nitrogenous bases of DNA are arranged along the sugar-phosphate backbone in a particular order (the DNA sequence), encoding all genetic instructions for an organism. Adenine (A) pairs with thymine $(\mathrm{T})$, while cytosine $(\mathrm{C})$ pairs with guanine $(\mathrm{G})$. The two DNA strands are held together by hydrogen bonds between the bases.

As a reactive chemical species DNA is the target of numerous physical and chemical agents. As a result of exposure to ionizing radiation a broad spectrum of DNA lesions is induced in cellular DNA (Fig. 17.4, Table 17.4), depending in type and quantity on the quality and dose of radiation. Radiochemical injuries of relevance for biological functions induce nucleotide base damages, cross-linking, and DNA single- and doublestrand breaks. These disorders have the capability to interfere with DNA replication as they may block the function of DNA polymerases. Nevertheless DNA is functionally more stable than the two other cellular macromolecules, RNA and protein. This stability can be attributed to the fact that

the primary structure of DNA is all that is needed for transfer of information;

DNA carries the information in duplicate due to its double-helical structure;

there are molecular mechanisms of different complexity to undo the DNA damage thus maintaining genetic integrity [38, 39].

In response to the harmful effects of environmental radiation, life has developed a variety of defense mechanisms, such as the increase in the production of stress proteins, and a variety of efficient repair systems for radiation-induced damages The immense importance of repair enzymes in sustaining genetic stability of exposed cells is obvious by a high degree of homology of particular enzymes occupied in different repair pathways from bacteria and yeast to man.

Only some enzymes simply reverse the damaged bases to their unmodified form. DNA repair by photolyase in the presence of light (photoreactivation) is the best studied repair reaction of this type to remove UV-induced DNA lesions from the genome. Genes coding for photolyase activities (PHR genes) were found in many prokaryotic and eukaryotic organisms, but not in all species [40]. Another example of direct damage reversal is repair of $O^{6}$-methyl guanine by transfer of the alkyl group from the DNA to a cysteine in a protein, an $\mathrm{O}^{6}$-methylguanine-DNA methyltransferase, which appears to be present in all living organisms [41]. A final example of direct damage reversal is the sealing of a subset of nicks in DNA by DNA ligase, which can only seal nicks having 5'-phosphates and 3'-hydroxyls.

The base excision repair system (BER) hydrolyses the 3' phosphodiester bond between the damaged base and deoxyribose moiety by a glycosylase, e.g an uracil glycosylase $[42,43]$. The resulting single nucleotide gap is recognised by an AP endonuclease and is filled in by DNA Pol I and then ligated. The nucleotide excision repair pathway (NER) is an elaborate repair system which removes bulky lesions from DNA [4446]. In E. coli, 3 proteins, the products of the $u v r A, u v r B$, and $u v r C$ genes, are responsible for damage recognition and nicking of the DNA approximately 7 nucleotides 5 ' to the damage. The fourth protein, the $u v r D$ gene product, known as DNA helicase II, displaces the damage-containing oligonucleotide, the single stranded gap is filled in by DNA Polymerase I and a ligase seals the newly synthesized DNA to the 


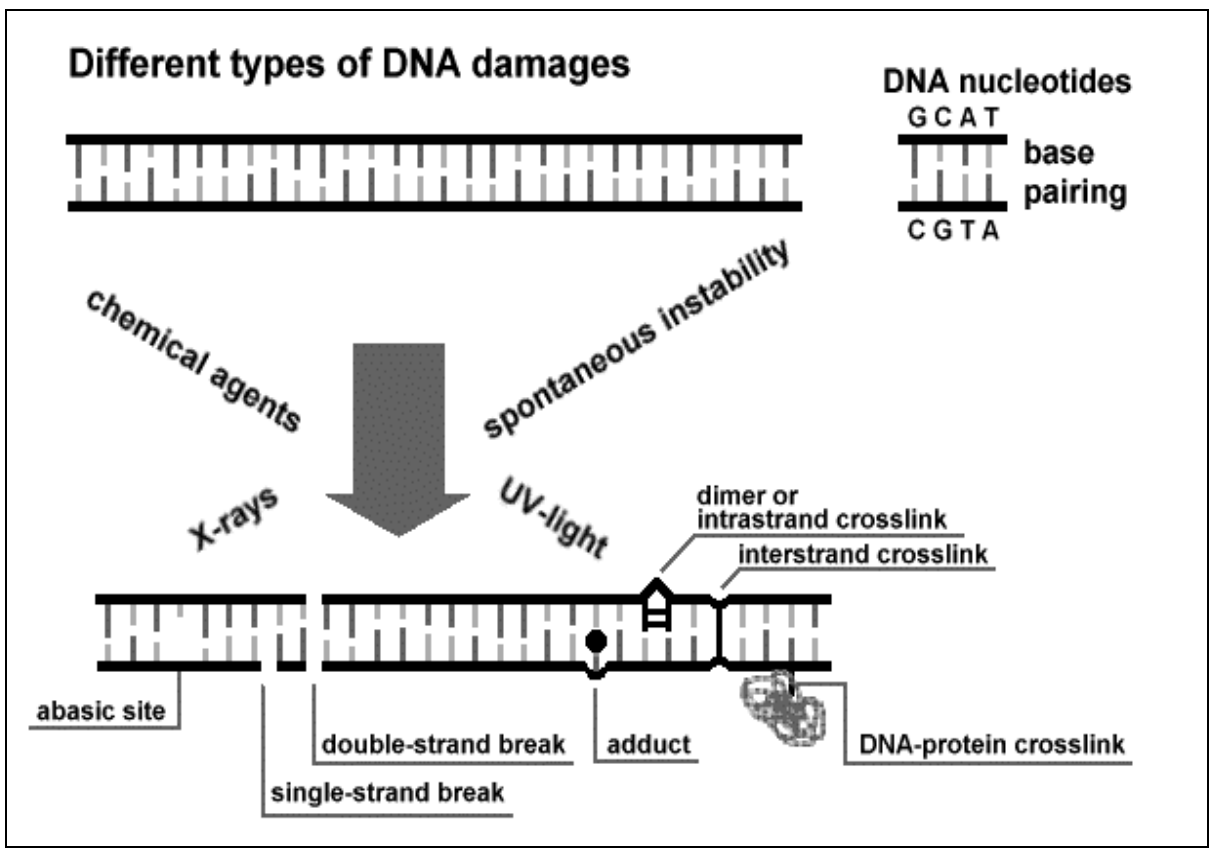

Fig. 17.4 Different types of DNA damage

Table 17.4 DNA lesions produced by different internal and external conditions and the pathways used by bacteria for their repair

\begin{tabular}{|c|c|c|}
\hline DNA lesion & caused by & repair mechanism \\
\hline $\begin{array}{l}\text { base mismatches, loops and } \\
\text { bubble structure }\end{array}$ & $\begin{array}{l}\text { replication errors } \\
\text { recombination }\end{array}$ & $\begin{array}{l}\text { base excision and } \\
\text { general mismatch repair }\end{array}$ \\
\hline deamination/depurination & heat & base excision \\
\hline oxidative damage & $\begin{array}{l}\text { oxidative metabolism } \\
\text { anoxia/hypoxia } \\
\text { ionizing radiation }\end{array}$ & base excision \\
\hline $\begin{array}{l}\text { alkylation/alkyl adducts } \\
\text { (nonbulky/bulky adducts) }\end{array}$ & $\begin{array}{l}\text { nitrogen mustard } \\
\text { polyaromatic compounds }\end{array}$ & $\begin{array}{l}\text { direct repair } \\
\text { base excision } \\
\text { nucleotide excision }\end{array}$ \\
\hline $\begin{array}{l}\text { intrastrand crosslinks } \\
\text { (Bulky adducts) }\end{array}$ & UV, cisplatin & $\begin{array}{l}\text { direct repair } \\
\text { nucleotide excision }\end{array}$ \\
\hline interstrand crosslinks & psoralen, malphalan & $\begin{array}{l}\text { nucleotide excision } \\
\text { recombination }\end{array}$ \\
\hline single-strand break & $\begin{array}{l}\text { ionizing radiation } \\
\text { oxidative stress } \\
\end{array}$ & ligation \\
\hline double-strand break & ionizing radiation & $\begin{array}{l}\text { ligation } \\
\text { recombination }\end{array}$ \\
\hline
\end{tabular}


old one. Both, BER and NER rely on the redundant information in the undamaged strand to correctly fill in the excision gap.

Of course complex DNA damages such as backbone or bulky base damage, require more complicated repair mechanisms such as multi-enzyme repair pathways.

If the genetic information in both DNA strands is damaged the recombinational repair pathway is helpful [47-49]. Non-excised lesions which persist until the onset of DNA replication lead to the formation of a gap in the newly synthesized DNA strand opposite the lesions. They can be filled by a recombinational exchange from the complementary old strand, where the respective information is available. The gaps which are now in the old strand are filled in by DNA polymerases using the newly synthesized strand as a template, followed by ligation of the newly synthesized DNA.

The inducible SOS response in E. coli and other bacteria is a highly mutagenic repair system which can be regarded as a driving force for evolution [50-52]. In bacteria any block to DNA replication caused by DNA damage lead to an excess of singlestranded DNA. This signal activates in E. coli the RecA protein, which then destroys a negatively acting regulatory protein (a repressor) that normally suppresses the transcription of the entire set of SOS response genes. Studies of mutant bacteria deficient in different parts of the SOS response indicate that the newly synthesized proteins increase cell survival as well as mutation rate by greatly rising the number of errors made in coding DNA sequences. This is most probably advantageous for long term survival because it produces a burst of genetic variability in the bacterial population and hence increases the chance that a mutant cell with increased fitness will arise.

In addition to repair systems, several other feedback controls operate to restrain the cell-cycle control in eukaryotic systems until particular conditions are satisfied. A well-characterized feedback control operates at the mitotic entry checkpoint to prevent cells with damaged DNA from entering mitosis until the damage is repaired [53, 54]. The response to DNA damage is usually studied using experimentally induced lesions in DNA, such as those created by X-rays. Many radiation-sensitive (rad) mutations have been isolated in budding yeast, and at least one, called rad 9, has been shown to code for an essential component of the feedback control mechanism. Mutants lacking rad 9 still possess the machinery for DNA repair, but they fail to delay in G2-phase of the mitotic cell cycle when they have been irradiated. As a result, they proceed into mitosis with damaged chromosomes; not surprisingly, they are killed by doses of radiation that normal cells would survive.

\subsection{Cellular Radiation Responses}

Two cellular functions are most important for the development and maintenance of life on Earth or other planets. These functions are cellular reproducibility and conservation of genetic stability. Both tasks can be disturbed by ionizing radiation with the result of cellular inactivation and mutation induction. 


\subsubsection{Radiation Sensitivity of Organisms}

Cell survival, in radiobiological terms, is understood as the ability for indefinite reproduction. Its impairment by radiation is fundamental for the assessment of radiation hazards. The colony forming ability (CFA) assay has long been used for unicellular microorganisms like bacteria, yeast and algae. CFA is of such central importance, that its loss is often equalized with cell death [55], which is strictly not correct since many other cell functions may still be undisturbed.

The surviving fraction of irradiated cells relative to that of non-irradiated cells is plotted on the ordinate log-arithmetically versus dose on a linear abscissa scale. With increasing dose the number of survivors decreases. The corresponding dose-effect curve declines continuously and can be simply characterized by two parameters. One is the $\mathrm{D}_{0}$ which is defined as the dose necessary to reduce survival to $\mathrm{e}^{-1}(=0.37)$, it can be calculated from the slope of the terminal straight part of the curve $(-1 /$ slope). The other parameter is the extrapolation number (n) which is calculated from the backward extrapolation of the straight proportion of the effect curve. Radiation sensitivity of different organisms can be compared on the basis of these parameters (Fig. 17.5, modified from [56], Table 17.5).

Radiation sensitivity of various organisms is generally related to the amount of genetic material [57]. The most resistant organisms are exclusively single-stranded viruses, followed by double-stranded viruses, bacteria, algae and yeast. For simple eukaryotes, it could be shown that haploid cells are about twice as sensitive as diploid cells [58]. Bacterial sensitivity to radiation is correlated with DNA base composition [59].

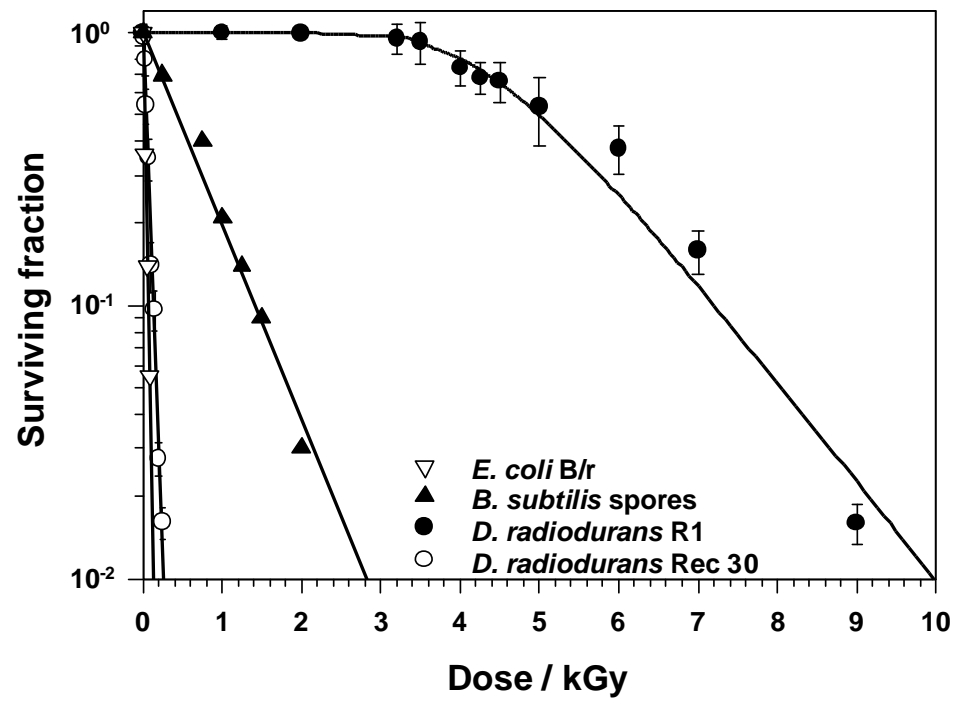

Fig. 17.5 Representative survival curves for Deinococcus radiodurans $R 1$ and its recombination deficient mutant Rec 30, compared to survival curves for spores of Bacillus subtilis and Escherichia coli $B / r$ following exposure to X-rays. (modified from [56]). 
Table 17.5 $\mathrm{D}_{0}$-values and cell DNA content for prokaryotic and eukaryotic organisms

\begin{tabular}{llcr}
\hline Name & Species & $\begin{array}{c}\text { DNA content } \\
(\mathbf{g} / \mathbf{c e l l})\end{array}$ & $\begin{array}{c}\mathbf{D}_{\mathbf{0}} \\
(\mathbf{G y})\end{array}$ \\
\hline T1-phage & Virus & $8.1 \times 10^{-17}$ & 2600 \\
Escherichia. coli B/r & Bacteria & $1.9 \times 10^{-14}$ & 30 \\
Bacillus subtilis cells & Bacilla & $7.7 \times 10^{-15}$ & 33 \\
\hline Saccharomyces cerevisiae & Yeast & $2.8 \times 10^{-14}$ & 150 \\
Chlamydomonas & Algae & $1.4 \times 10^{-13}$ & 24 \\
Human & Human & $5.4 \times 10^{-13}$ & 1.4 \\
\hline
\end{tabular}

The variety of cellular processes involved in the repair of damaged DNA have to be considered to be primarily responsible for radiation resistance. For bacterial cells as well as for yeasts and higher eukaryotes $\mathrm{D}_{0}$-values from repair proficient and repair deficient cells obtained from the same species differ more than a factor of 100 from each other [60].

The most radiation resistant bacterium known is Deinococcus radiodurans. It was originally isolated from samples of canned meat that were thought to be sterilized by high doses of $\gamma$-radiation [61]. Typically, it is found in locations where most other bacteria have died from extreme conditions, ranging from the shielding pond of a radioactive cesium source to the surfaces of Arctic rocks. Researchers examined the bacterium's cellular repair genes and discovered that, while D. radiodurans contained the usual complement of repair genes found in other radiation-sensitive bacteria, it has an unusually large redundancy of repair functions [62]. Furthermore, the regulation of its repair activities is highly coordinated with the cell cycle. In Figure 17.5 the radiation sensitivity of the highly radiation resistant bacterium $D$. radiodurans $\mathrm{R} 1$ is compared with that of a mutant $D$. radiodurans $\operatorname{Rec} 30$, that is deficient in DNA repair and two other bacterial representatives: spores of B. subtilis and cells of $E$. coli. The $\mathrm{D}_{37}$ dose for the $E$. coli culture is $30 \mathrm{~Gy}$, which is approximately 200 times lower than that of $D$. radiodurans. $D$. radiodurans has a characteristic shoulder of resistance to approximately $3 \times 10^{3} \mathrm{~Gy}$; at doses below that value there is no loss of viability although up to about 100 double strand breaks have been induced in the chromosome of each cell [56]. Above $5 \times 10^{3} \mathrm{~Gy}$, there is an exponential decline in viability and a $\mathrm{D}_{37}$ dose of between 6-7 $\times 10^{3}$ Gy for cultures in exponential phase. It is remarkable, that in $D$. radiodurans $\operatorname{Rec} 30$ that has lost its repair capacities the radiation sensitivity reaches similar values as in E. coli [56].

\subsubsection{Mutation Induction}

Mutations, alterations of the genetic material, result in a permanent change in the expression of genes. This is known as a naturally occurring phenomenon, which occurs 
spontaneously with a rare but gene-dependent fixed frequency, thereby being the driver of biological evolution.

Certain agents are able to increase the rate of mutation, ionizing radiation being most effective $[63,64]$. Radiation acts by ionizing the bases in the DNA chain, this is in particular especially important during DNA synthesis. Ionization of one ore more of the bases or interactions of bases with free radicals may alter base structures in that way that they no longer possess the characteristics they had before. Under such circumstances, a mismatch base pairing might occur which in turn might result in an altered sequence of bases in the newly synthesized chain. Deletions occur, if sufficient numbers of ionizations or interactions with free radicals take place. Mutational frequency increases linearly with radiation dose. It increases with increasing LET reaching a peak and diminishing thereafter. Except for very rare cases, which give rise to evolutionary advancements, most mutations are detrimental to cells as they bring about sharp deviations from the status quo. Such mutational changes are negative mutations, resulting in a cellular loss of function impairing viability by a shortened life-span (years, days, minutes) of the organism [65]. Some genes are so important, that their changes bring death essentially immediately.

\subsubsection{Factors Influencing Cellular Radiation Effects}

It could be deduced from the aforementioned facts, that the biological effects of ionizing radiation are not rigid and precise. There are variations in the degree of response of organisms, even among populations of individuals of the same species. Some of the factors influencing the response to radiation are the subject matter of this part.

\subsubsection{Dose Rate and Dose Fractionation}

For most biological effects the effectiveness of a given dose will be related to the rate at which the dose is delivered. Generally speaking, the effectiveness of a given dose of sparsely ionizing radiation is reduced as the time to deliver that dose is increased [66]. The effectiveness of any given radiation is not only reduced, when the dose-rate is reduced. There will be an alteration in the magnitude of the effect when the same radiation is delivered at interrupted intervals, in fractions with some time between each fraction [67]. The difference in the magnitude of effects observed as a function of dose rate or of fractionating the dose are usually explained by recovery phenomena which are based upon cellular repair of DNA damages [39, 59].

\subsubsection{Oxygen Pressure}

The tension of oxygen in cells at the time of irradiation is an important determinant of the degree of severity of radiation damage, as in presence of oxygen, the amount of oxidizing radicals increases, due to the fact that the oxygen molecule is a reaction partner for the primary radiolytic products (see 17.4, Eq. 17.7). Oxygen always enhances the action of radiation [68]. For comparing radiation effects on organisms with different metabolic conditions (anoxia, hypoxia, hyperoxia), the oxygen enhancement 
ratio describes the surplus of effect in presence of oxygen $\left(+\mathrm{O}_{2}\right)$ over the effect in absence of oxygen $\left(-\mathrm{O}_{2}\right)$.

\subsubsection{Chemicals as Radioprotectors or Radiosensitizers}

A major influence on cellular radiation sensitivity in terms of protective effects comes from cellular constituents which serve as radical scavengers [69]. Examples for this kind of reaction are alcohols, e.g. ethyl alcohol which react with radicals according to Eq. 17.10. The resultant alcohol radical is much less reactive than the ${ }^{+} \mathrm{OH}$ so that the net effect is reduced [70].

$$
\mathrm{HO}^{\bullet}+\mathrm{CH}_{3} \mathrm{CH}_{2} \mathrm{OH} \longrightarrow \mathrm{CH}_{3} \mathrm{C}^{\bullet} \mathrm{HOH}+\mathrm{H}_{2} \mathrm{O}
$$

Many other substances react as radioprotectors by radical scavenging in living organisms, e.g. cysteine, cysteamine and dimetyl sulfoxid [71].

Other substances have the capacity to worsen the cellular radiation effect. Among them are oxygen mimetic substances like $\mathrm{N}$-acetyl-maleimide and stable free radicaltype sensitizes like triacetonamine-N-oxyl [72]. Furthermore chemicals which interact with cellular repair systems, such as novobiocin and 9- $3-D$-arabinofuranosyladenine (ara A) sensitize exposed cells towards the detrimental effects of ionizing radiation [73].

\subsubsection{Metabolic Rate and Temperature}

The development of radiation injury is dependent on metabolic rate. Accordingly, varying the metabolic rate will bring about variations in the rate of development of radiation effects. If metabolism is speeded up the lethal effects of radiation are enhanced, while retarding the metabolic rate results in less radiation effects [74-76]. Metabolic active and metabolic resting cells of the same species differ in their radiosensitivity by a factor of about 10. Irradiation at reduced temperatures can result in opposite effects. Due to a metabolic slow-down, less cellular radiation effects are to be expected for temperatures down to $4{ }^{\circ} \mathrm{C}$. However, due to reduced activities of repair enzymes, the radiation response can be worsened. If temperatures drop well below $0{ }^{\circ} \mathrm{C}$ during exposure to ionizing radiation the reduced diffusion ability of radials leads to a protective effect. In frozen water the indirect action of radiation is reduced and the damaging power towards DNA is attributed mainly to the direct effect [77].

\subsubsection{Proliferation Rate}

Cell populations that are rapidly proliferating are more sensitive to radiation than populations having lower generation turnovers. Radiation sensitivity depends on the cell cycle stage in which the cells are exposed. The mitotic process of eukaryotic cells is a relatively radiosensitive phase in a cell's life $[78,79]$. This is well documented for sparsely ionizing radiation. Radiation also slows down the progression of cells through the cycle [80]. Sensitivity variations as a function of cell cycle stage are not only found for colony formation but also for chromosome aberrations or mutation induction. The 
highest yield of mutations is found for cells exposed during G1-phase with the S-phase being quite resistant.

\subsection{The Chances of Life Surviving Space Radiation Conditions}

\subsubsection{Interplanetary Transfer of Life}

Te question of the chances of interplanetary transfer of life has been elucidated by Horneck et al. in Chapter 4 of this volume. From the radiation biology point of view, the chances for life to survive space radiation conditions are not too bad.

As shown by space experiments and ground experiments with accelerated heavy ions [81-85], B. subtilis spores can survive even a central hit of a heavy ion of cosmic radiation, which are speculated to be the ultimate limit on the survival of spores in space because they penetrate even thick shielding. Due to the comparative low fluxes of heavy ions in our galaxy a spore can escape from a hit by a HZE particle (e.g. iron of LET $>100 \mathrm{keV} / \mu \mathrm{m}$ ) for hundred thousands up to 1 million of years. This time span meets the estimates which are calculated for medium-sized rocks to travel from one planet of our solar system to another, e.g. from Mars to Earth [86]. For transfer of microscopically small particles only a few months have been estimated to be sufficient for an interplanetary passage [87].

As already mentioned, the component of the space radiation environment that presents the largest uncertainty in predictions are the SPEs accompanying solar flares, which develops rapidly but generally last for no more than some hours. Concerning shielding against radiation in space, less than $0.5 \mathrm{~g} / \mathrm{cm}^{2}$ is required against the diffuse X-rays, but the high energy particles in SPEs and the GCR particles are difficult to shield due their high penetration depth. Experiments with B. subtilis suggest, however, an estimated density of $1.8 \mathrm{~g} / \mathrm{cm}^{2}$ of meteorite material of 2 to $3 \mathrm{~m}$ thickness to shield the spores sufficiently. Such calculations show that yet after 25 million years in space, a substantial fraction of a bacterial spore population $\left(10^{-6}\right)$ would survive the exposure to cosmic radiation if shielded under comparable conditions.

\subsubsection{Putative Habitats on Other Planets}

The unusual extent of radiation resistance, which is displayed by the bacterium $D$. radiodurans has already been mentioned. Because there are no known radioactive environments on Earth that can explain the evolution of $D$. radiodurans's resistance to radiation, there is general agreement that this organism's resistance to radiation is a secondary characteristic developed in response to some other environmental stress. The consensus view is that the mechanisms that evolved to permit survival in very dry environments additionally confer resistance to radiation [88]. It is possible that other desiccation-resistant micro-organisms, not yet described as radiation-resistant, could exist in planetary biospheres. Despite the discrediting of the often repeated claim that live bac- 
teria were recovered from Surveyor 3's camera after surviving on the Moon's surface from 1967-1969, experiments conducted aboard a variety of spacecraft including the European Retrievable Carrier (EURECA) and the Long Duration Exposure Facility (LDEF) indicate that a variety of common terrestrial bacteria are able to withstand the free space environment for periods as long as 6 years $[89,90]$. Since the radiationresistance characteristics of many common organisms (and most extremophiles) are unknown, it is conceivable that many bacteria classified as desiccation- and/or radiation-resistant have the capacity to survive also in harsh radiation environments.

Although the radiation dose rate on the surface of Mars is about 100 times higher than on Earth (see 17.2, Table 17.3), it cannot be considered as a limiting factor for microbial life on Mars, as discussed by Gilichinsky in Chapter 8 of this volume. As already described, D. radiodurans tolerates radiation doses up to $3 \times 10^{3}$ Gy without any significant inactivation. The annual dose on Mars is $3-4 \times 10^{4}$ times lower, a fact which would not impair growth of such microorganisms if they possess potent DNA repair systems. Even vegetative cells of $B$. subtilis or $E$. coli cells with a $\mathrm{D}_{0}$ of about 30 Gy would be able to survive radiation exposure under Martian conditions for extended periods of time.

The nowadays harsh conditions for life on the Marian surface (low atmospheric pressure, no oxygen, low temperature) would require life to persevere in stages of reduced metabolic activity or even in resting stages (reduced or absent proliferation rate, reduced water content, cells in frozen state). This in turn are conditions which modify radiation effects considerably (reduced diffusion capacity of radiolysis products, reduced indirect radiation effects, less DNA damage per dose) resulting in increased cellular radiation resistance. From the radiobiology point of view, simple life forms in dormant states are ideal candidates to survive even harsh radiation conditions for extended time periods. For the Martian radiation environment of about yearly $90 \mathrm{mGy}$ (calculating $57 \mathrm{mGy} / \mathrm{a}$ of GCR and one SPR event of October 1989 size of 32 mGy per year) it would last 6600 years, to accumulate a dose of $600 \mathrm{~Gy}$ (resulting in a surviving fraction of 0.37 ) in spores of Bacillus subtilis. Even after about $1 \times 10^{6}$ years (accumulated dose of $8 \mathrm{kGy}), 1$ out of $10^{6}$ irradiated spores can be expected to survive Martian surface radiation conditions. For these calculations, the modification of cellular radiation response based on the factors described in 17.5.3 has not been considered.

Other than for the planet Mars, the Jupiter moon Europa displays an extremely harsh radiation field near its surface (see 17.2.3, Fig. 17.2), which is a key factor governing the viability of organisms. For a dose rate of 3-4 Gy/min, E. coli cells and vegetative cells of B. subtilis would be inactivated within some 10 minutes. Under these conditions it can be calculated, that only 1 out of $10^{6}$ cells would survive an acute irradiation of 2 hrs. Even spores of B. subtilis will be expected to yield a deadly dose of ionizing radiation (survival fraction of $10^{-6}$ ) within $40 \mathrm{hrs}$.

On Europa, life-sustaining, near-surface environments may exist within or under regions of water ice (see Chap. 7, Greenberg), since ice will provide microbes with some degree of radiation protection. A psychrophilic or psychrotolerant microbial species (see Chap. 9, Wagner et al., Chap. 10, Stackebrandt and Brambilla) with the radioresistance of $D$. radiodurans would grow continuously without any effect on its growth rate in $1 \mathrm{~mm}$ depth of Europa's surface ice (Fig. 17.2), where the dose rate is reduced to about $1 \mathrm{~Gy} / \mathrm{min}$. At $10 \mathrm{~cm}$ depth the radiation environment in the Europan ice has 
been reduced by a factor of $5 \times 10^{3}$ to $\sim 50$ Gy per month $\left(1 \times 10^{-3} \mathrm{~Gy} / \mathrm{min}\right)$, a radiation dose, which can be tolerated by most bacteria. For microorganisms living below a shallow depth at Europa - at most a few tens of meters below the surface - radiation itself is no longer a significant environmental factor. At greater depths, the radiation environment continues to decrease, reaching values similar to those in Earth's biosphere below depths of 20 to $40 \mathrm{~m}$.

\subsection{References}

1 D.E. Lea (Ed.) Action of radiation on living cells, Cambridge University Press, London \& New York, 1955, 416 pp.

2 A. Nasim, A.P. James, in: DJ Kushner (Ed.) Microbial Life in Extreme Environments, Academic Press, London New York San Francisco, 1978, pp. 409.

3 J.A. Simpson, Ann. Rev. Nucl. Part. Sci. 33, 323 (1983).

4 W. Heinrich, J. Beer, Adv. Space Res. 4(10), 133 (1984).

5 G.D. Badhwar, F.A. Cucinotta, P.M. O'Neill, Radiat. Res. 138, 201 (1994).

6 S.W. Kahler, N.R. Sheeley Jr., R.A. Howard, M.L. Koomen, D.J. Michels, R.E. McGuire, T.T. von Rosenvinge, D.F. Reames, J. Geophys. Res. 89, 9683 (1984).

7 G. Gloeckler, Rev. of Geophys. 17, 569 (1979).

8 M.A. Shea, D.F. Smart, J. Geomag. Geoelect. 42, 1107 (1990).

9 J. Feynman, T.P. Armstrong, L. Dao-Gibner, S. Silverman, J. Spacecraft 27, 403 (1990).

10 J.A. van Allen, L.A. Frank, Nature, 183, 430 (1959).

11 G.D. Badhwar, D.E. Robbins, Adv. Space Res. 17(2), 151 (1996).

12 K. O'Brien, W. Friedberg, H.H. Sauer, D.F. Smart, Environ. Int. 2 Suppl. 1, S9 (1996).

13 W. Schimmerling, J.W. Wilson, F.E. Nealy, S.A. Thibeault, F.A. Cucinotta, J.L. Shinn, M. Kim, R. Kiefer, Adv Space Res. 17(2), 31 (1996).

14 J. Miller, Adv Space Res. 14(10), 831 (1994).

15 United Nations Scientific Committee on the Effects of Atomic Radiation, Sources and Effects of Ionizing Radiation, Volume I: Sources, UNSCEAR 2000 Report to the General Assembly, with Scientific Annexes, United Nations Sales Publication, Sales No. E.00.IX.3, 2000.

16 J.A. Sorenson, Semin. Nucl. Med. 6, 158 (1986).

17 H. Morishima, T. Koga, K. Tatsumi, S. Nakai, T. Sugahara, Y. Yuan, L. Wie, J. Radiat. Res. (Tokyo) 41, 9 (2000).

18 A.R. Gopal-Ayengar, G.G. Nayar, K.P. George, K.B. Mistry, Indian J. Exp. Biol. 8, 313 (1970).

19 A. Malanca, V. Pessina, G. Dallara, Health Phys. 65, 298 (1993).

20 Bayerisches Staatsministerium für Landesentwicklung und Umweltfragen. Strahlenschutz - Radioaktivität und Gesundheit. München, 1991.

21 E.J. Conway, L.W. Townsend, in: E.B. Pritchard (Ed.) Mars: past, present, and future, American Institute of Aeronautics and Astronautics, Washington, DC, 1992, pp. 239 (Progress in astronautics and aeronautics, vol. 145).

22 L.C. Simonsen, J.E. Nealy, L.W. Townsend, J.W. Wilson, J. Spacecr. Rockets. 27, 353 (1990).

23 L.C. Simonsen, J.E. Nealy, NASA-TP 3300 (1993) 
24 H.M. Fischer, E. Pehlke, G. Wibberenz, L.J. Lanzerotti, J.D. Mihalov, Science 272, 856 (1996).

25 M.A. McGrath, Science 278, 268 (1997).

26 Committee on Planetary and Lunar Exploration, Space Studies Board, Commission on Physical Sciences, Mathematics, and Applications. A Science Strategy for the Exploration of Europa. National Academy Press, Washington, DC, USA, 1999.

27 Task Group on the Forward Contamination of Europa, Space Studies Board, Commission on Physical Sciences, Mathematics, and Applications, National Research Council. Preventing the Forward Contamination of Europa. National Academy Press, Washington, DC, USA, 2000.

28 D.T. Goodhead, J. Radiat. Res. 40 Suppl. 1 (1999).

29 C.F. Powell, P.H. Fowler, D.H. Perkins (Eds.) The study of elementary Particles by the Photographic Method, Pergamon Press, London New York Paris Los Angeles, 1959, pp. 669.

30 S.M. Pimblott, J.A. LaVerne, Radiat. Res. 129, 265 (1992).

31 C.D. Jonah, Radiat Res 144, 141 (1995).

32 J.A. LaVerne, Radiat. Res. 153, 196 (2000).

33 A. Mozumder, Radiat. Res. Suppl. 8, S33 (1985).

34 K.F. Baverstock, W.G. Burns, Radiat Res 86, 20 (1981).

35 F.C. Steward, R.D. Holsten, M. Sugii, Nature 213, 178 (1967).

36 H.B. Michaels, J.W. Hunt, Radiat Res 74, 23 (1978).

37 G.D. Jones, T.V. Boswell, J. Lee, J.R. Milligan, J.F. Ward, M. Weinfeld, Int. J. Radiat. Biol. 66, 441 (1994).

38 W. Vermeulen, J. Hoeijmakers, D. Bootsma, HELIX, Amgens Magazine of Biotechnology 5, 22 (1996).

39 C. Baumstark-Khan, in: C. Baumstark-Khan, S. Kozubek, G. Horneck (Eds.) Fundamentals for the Assessment of Risks from Environmental Radiation. Kluwer Academic Publisher, Dordrecht Boston London, 1999, pp. 103.

40 D.J. Davies, S.A. Tyler, R.B. Webb, Photochem. Photobiol. 6, 371 (1970).

41 T.H. Bestor, G.L. Verdine, Current Opinion in Cell Biology 6, 380 (1994).

42 O.D. Scharer, J. Jiricny, Bioessays 23, 270 (2001).

43 S.S. Parikh, C.D. Mol, J.A. Tainer, Structure 5, 1543 (1997).

44 A.S. Balajee, V.A. Bohr, Gene 250, 15 (2000).

45 A. Sancar, M.S. Tang, Photochem. Photobiol. 57, 905 (1993).

46 S. Hoare, Y. Zou, V. Purohit, R. Krishnasamy, M. Skorvaga, B. VanHouten, N.E. Geacintov, A.K. Basu, Biochemistry 39, 12252 (2000).

47 T. Lindahl, R.D. Wood, Curr. Opin. Cell Biol. 1, 475 (1989).

48 A. Kuzminov, Microbil. Mol. Biol. Rev. 63, 751 (1999).

49 P. Baumann, S.C. West, Trends Biochem. Sci. 23, 247 (1998).

50 M. Radman, Basic Life Sci. 5A, 355 (1975).

51 F.W. Perrino, D.C. Rein, A.M. Bobst, R.R. Meyer, Mol. Gen. Genet. 209, 612 (1987).

52 A. Bouyoub, G. Barbier, J. Querellou, P. Forterre, Gene 167, 147 (1995).

53 T.A. Weinert, L.H. Hartwell, Science 241, 317 (1988).

54 D. Lydall, T. Weinert, Science 270, 1488 (1995).

55 G.W. Barendsen, BJR Suppl. 24, 53 (1992).

56 H. Zimmermann, Wirkung locker- und dichtionisierender Strahlung auf Zellen von Deinococcus radiodurans. DLR-FB 94-14, DLR, Köln, Germany, 1994.

57 H.S. Kaplan, L.E. Moses, Science 145, 21 (1964). 
Pamphile, M. Crosby, M. Shen, J.J. Vamathevan, P. Lam, L. McDonald, T. Utter-
back, C. Zalewski, K.S. Makarova, L. Aravind, M.J. Daly, K.W. Minton, R.D.
Fleischmann, K.A. Ketchum, K.E. Nelson, S. Salzberg, H.O. Smith, J.C. Venter, C.M. Fraser, Science 286, 1571 (1999).

63 R.F. Kimball, Mutat. Res. 55, 85 (1978).

64 B.A. Bridges, Int. J. Radiat. Biol. Relat. Stud. Phys. Chem. Med. 37, 93 (1980).

65 M.B. Baird, A.M. Clark, Exp Gerontol 6, 1 (1971).

66 E.J. Hall, Int. J. Radiat. Biol. 59, 595 (1991).

67 J.H. Hendry, R.I. Mackay, S.A. Roberts, N.J. Slevin, Int. J. Radiat. Biol. 73, 383 (1998).

68 M. Quintiliani, Int. J. Radiat. Oncol. Biol. Phys. 5, 1069 (1979).

69 H. Tomita, M. Kai, T. Kusama, A. Ito, Radiat. Environ. Biophys. 36, 105 (1997).

70 S.M. Afzal, P.C. Kesavan, Int. J. Radiat. Biol. Relat. Stud. Phys. Chem. Med. 35, 287 (1979).

71 D.R. Singh, J.M. Mahajan, D. Krishnan, Mutat. Res. 37, 193 (1976).

72 E.L. Powers, Int. J. Radiat. Biol. Relat. Stud. Phys. Chem. Med. 42, 629 (1982).

73 A. Collins, Int. J. Radiat. Biol. Relat. Stud. Phys. Chem. Med. 51, 971 (1987).

74 B.S. Rao, M.S. Murthy, N.M. Reddy, P. Subrahmanyam, U. Madhvanath, Mutat. Res. 28, 183 (1975).

75 S. Matsumoto, Can. J. Microbiol. 17, 179 (1971).

76 B.A. Bridges, M.J. Ashwood-Smith, R.J. Munson, Biochem. Biophys. Res. Commun. 35, 193 (1969).

77 J. Hüttermann, M. Lange, J. Ohlmann, Radiat. Res. 131, 18 (1992).

78 R. Fingerhut, J. Kiefer, F. Otto, Mol. Gen. Genet. 193, 192 (1984).

79 N.L. Oleinick, Radiat. Res. 51, 638 (1972).

80 A. Maity, W.G. McKenna, R.J. Muschel, Radiother. Oncol. 31, 1 (1994).

81 H. Bücker, G. Horneck, in: O.F. Nygaard, H.I. Adler, W.K. Sinclair (Eds.) Radiation Research, Academic Press, New York, 1975, pp. 1138.

82 K. Baltschukat, G. Horneck, Radiat. Environ. Biophys. 30, 87 (1991).

83 U. Weisbrod, H. Bücker, G. Horneck, G. Kraft, Radiat. Res. 129, 250 (1992).

84 M. Schäfer, Int. J. Radiat. Biol 69, 459 (1996).

85 H. Zimmermann, M. Schäfer, C. Schmitz, H. Bücker., Adv. Space Res. 14(10), 213 (1994).

86 H.J. Melosh, Nature 332, 687 (1988).

87 M.A. Moreno, Nature 336, 209 (1988).

88 V. Mattimore, J.R. Battista, J. Bacteriol. 177,5232, (1996).

89 R.L. Mancinelli, M.R. White, L.J. Rothschild, Adv. Space Res. 22(3), 327, (1998).

90 G. Horneck, Adv. Space Res. 22(3), 317, (1998). 